\title{
It's a Matter of Respect
}

\author{
Lauge Sokol-Hessner, MD*
}

Division of General Medicine and Primary Care and the Department of Health Care Quality, Beth Israel Deaconess Medical Center and Harvard Medical School, Boston, Massachusetts.

Serious illnesses challenge patients, their families, clinicians, and the health systems that care for them. In this issue of the Journal of Hospital Medicine, Cowen and coauthors shed light on the experience of inpatients on medical and surgical services with a high risk of mortality on admission, as measured by Hospital Consumer Assessment of Healthcare Providers and Systems Surveys (HCAHPS). ${ }^{1}$ In their study population, even after adjustment for some confounders, these patients tended to rate responsiveness of hospital staff and communication by doctors lower than patients with a low risk of mortality on admission.

A more generalizable frame than admission risk of mortality is to consider the patients they identified as high risk to be "patients with serious illness." Using this frame will be helpful in understanding the implications of their results, but it is important to acknowledge that for several reasons, the data in this study may not represent the entire population of seriously ill patients. First, there may be patients at lower risk of mortality who would qualify as having a serious illness. Second, the study's data were from only a few hospitals in 1 healthcare system. Third, 93\% of patients at high risk of mortality on admission did not return surveys. Despite these significant limitations, there are still important insights to be gleaned from their work.

Before exploring what they found, it is also important to note that it can be challenging to know what to make of HCAHPS scores. For instance, patients with higher HCAHPS scores have been found to have higher costs of care and higher mortality. ${ }^{2}$ Satisfied patients are not clearly better off. However, what if, for purposes of learning, the scores serve as a window into the seriously ill patient's experience, helping inform an understanding of the challenges and opportunities for improvement?

One of the key findings of this study was that seriously ill patients rated responsiveness by hospital staff worse than those who were not as ill. Patients were asked 2 questions as part of the composite measure:

*Address for correspondence and reprint requests: Lauge SokolHessner, MD, 330 Brookline Avenue, W/PBS-2, Boston, MA 02215; Telephone: 617-754-4677; Fax: 617-632-0215; E-mail: Ihessner@bidmc. harvard.edu

Received: April 12, 2016; Accepted: April 21, 2016 2016 Society of Hospital Medicine DOI 10.1002/jhm.2609 Published online in Wiley Online Library (Wileyonlinelibrary.com).
"During this hospital stay, after you pressed the call button, how often did you get help as soon as you wanted it?" "How often did you get help in getting to the bathroom or in using a bedpan as soon as you wanted?"

It is not difficult to imagine how seriously ill patients might have more intense care needs that would result in more requests for help, nor is it difficult to imagine how some proportion of those requests might not be handled in a timely fashion. Objective research shows higher rates of call button requests have been associated with slower response times, and it appears there is a complex relationship with staffing levels and the intensity of work on the floor. ${ }^{3}$ Certainly there may be times that patients want a quick response after pressing a call button, but do not need one, and a lot of time could be spent discussing these quandaries. However, there are also times when a patient describes having called for help, really needing it, yet no one came. At least some of the time, responsiveness is a matter of respect, especially considering the vulnerability of seriously ill patients and the issue of dignity around toileting.

Another key finding was about communication by doctors, and the questions patients answered were: "During this hospital stay, how often did doctors treat you with courtesy and respect?" "During this hospital stay, how often did doctors listen carefully to you?" "During this hospital stay, how often did doctors explain things in a way you could understand?"

There is a growing and important body of literature about communication with seriously ill patients. ${ }^{4}$ Consider some of the data about patients with advanced cancer. Evidence suggests the majority of such patients want to know their prognosis, and that when it is discussed it does not worsen the patientphysician relationship, sadness, or anxiety. ${ }^{5}$ Despite this, among physicians who have formulated a prognosis for patients with advanced cancer, even if they were asked directly by those patients about their prognosis, $23 \%$ of the time they would communicate no prognosis. Forty percent of the time they would communicate a different prognosis than what they had formulated, with $70 \%$ of those being optimistically discrepant. ${ }^{6}$ Although data are more limited, there is evidence that hospitalists are similarly wary to acknowledge when patients are at risk of dying. ${ }^{7}$

Although certainly other aspects of communication by doctors with seriously ill patients contributed to this 
study's findings, this issue of acknowledging and discussing the serious illness itself is important to highlight. Healthcare professionals have an ethical obligation to respect patients' autonomy by helping them make informed decisions about their care. Having these conversations can be challenging, but training programs and conversation guides are showing promise. ${ }^{8}$ If health professionals do not try to ensure that seriously ill patients understand their diagnosis, prognosis, and full range of treatment options in patientcentered ways, then by definition patients cannot be making informed decisions. It is a matter of respect.

This study's most important contribution is how it focuses attention on the domains of responsiveness by hospital staff and communication by doctors, encouraging a deeper dive to consider what else is known about these topics. Allowing that the lower scores from seriously ill patients might reflect more than just poor satisfaction reveals that at least some proportion of the time, these patients are experiencing disrespect. The work then becomes clear: What are the ways in which health professionals should reliably be demonstrating respect toward patients, especially those who are seriously ill? It is there, in the process of developing a reliable practice of respect, that consensus about how to improve the patient experience is most likely to be found.

Disclosure: Nothing to report.

\section{References}

1. Cowen ME, Czerwinski J, Kabara J, Blumenthal DU, Kheder S, Simmons S. The risk-outcome-experience triad: mortality risk and the Hospital Consumer Assessment of Healthcare Providers and Systems Survey. J Hosp Med. 2016;11(9):628-635.

2. Fenton JJ, Jerant AF, Bertakis KD, Franks P. The cost of satisfaction: a national study of patient satisfaction, health care utilization, expenditures, and mortality. Arch Intern Med. 2012;172(5):405-411.

3. Tzeng H-M, Larson JL. Exploring the relationship between patient call-light use rate and nurse call-light response time in acute care settings. Comput Inform Nurs. 2011;29(3):138-143.

4. Bernacki RE, Block SD; American College of Physicians High Value Care Task Force. Communication about serious illness care goals: a review and synthesis of best practices. JAMA Intern Med. 2014; 174(12):1994-2003.

5. Enzinger AC, Zhang B, Schrag D, Prigerson HG. Outcomes of prognostic disclosure: associations with prognostic understanding, distress, and relationship with physician among patients with advanced cancer. J Clin Oncol. 2015;33(32):3809-3816.

6. Lamont EB, Christakis NA. Prognostic disclosure to patients with cancer near the end of life. Ann Intern Med. 2001;134(12):10961105 .

7. Anderson WG, Kools S, Lyndon A. Dancing around death: hospitalist-patient communication about serious illness. Qual Health Res. 2013;23(1):3-13.

8. Bernacki R, Hutchings M, Vick J, et al. Development of the Serious Illness Care Program: a randomised controlled trial of a palliative care communication intervention. BMJ Open. 2015;5(10):e009032. 